Authors have nothing to disclose with regard to commercial support.

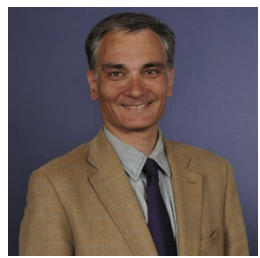

\section{ECHOCARDIOGRAPHIC CORRELATES TO RIGHT VENTRICULAR DYSFUNCTION AND FAILURE}

To the Editor:

Bartfay and colleagues recently presented their retrospective case series of 20 patients with empirical pre-emptive biventricular mechanical circulatory support. ${ }^{1}$ They discuss briefly the value of 2 simple scoring systems for prediction of right ventricular (RV) failure. $^{2,3}$ The associated editorial by Takayama ${ }^{4}$ raises a number of germane points in the quest for successful management of biventricular failure.

We hereby add our thoughts regarding the somewhat elusive and intertwined concepts of RV failure and RV dysfunction. We are concerned that none of the echocardiography markers of RV function, such as tricuspid annular plane systolic excursion $<17 \mathrm{~mm}$, pulsed Doppler $\mathrm{S}^{\prime}$ wave $<9.5 \mathrm{~cm} / \mathrm{sec}$, RV fractional area change $<35 \%$, and RV ejection fraction $<45 \%$, have been adequately investigated as predictors of patient-centered outcomes after ventricular assist device insertion. ${ }^{3}$ The role of echocardiographic markers of global RV systolic function (eg, RV index of myocardial performance, Doppler tissue imaging-derived $S^{\prime}$ wave velocity, RV strain, and RV strain rate or 3-dimensional echocardiographic RV ejection fraction) ${ }^{5}$ as early predictors of RV dysfunction or failure in patients with a left ventricular assist device (LVAD) has not been adequately investigated. There are no validated early echocardiographic markers of $\mathrm{RV}$ dysfunction to inform to decision to apply a biventricular assist device or not.

Very recently, this very issue of prediction of RV failure after LVAD implant was linked to RV deformation interrogated by speckle-tracking echocardiography in a small retrospective study. ${ }^{6}$ Also, a meta-analysis of 36 observational studies summarized aspects of the issue, emphasizing

The Editor welcomes submissions for possible publication in the Letters to the Editor section that consist of commentary on an article published in the Journal or other relevant issues. Authors should: • Include no more than 500 words of text, three authors, and five references. • Type with double-spacing. $\bullet$ See http://jtcs.ctsnetjournals.org/ misc/ifora.shtml for detailed submission instructions. • Submit the letter electronically via jtcvs.editorialmanager.com. Letters commenting on an article published in the JTCVS will be considered if they are received within 6 weeks of the time the article was published. Authors of the article being commented on will be given an opportunity of offer a timely response ( 2 weeks) to the letter. Authors of letters will be notified that the letter has been received. Unpublished letters cannot be returned. the potential role of qualitative assessment of RV performance, RV/left ventricle diameter ratio, and RV free wall longitudinal 2-dimensional strain in RV failure risk prediction models. ${ }^{7}$

It would be very interesting to explore further the role of echocardiography (eg, temporal changes of RV function in LVAD patients, daily echocardiography, and the natural history of RV dysfunction in LVAD survivors) in identifying LVAD patients at risk of RV failure early to risk-stratify them.

There is a need for a personalized medicine approach in such a high-risk patient population. We accept of course that echocardiographic criteria alone will never adequately predict RV failure, or more importantly, RV nonfailure. Hemodynamic parameters will always need to be incorporated into any risk assessment of RV dysfunction.

Vasileios Zochios, MD, MRCP $(U K)^{a, b}$ Aristotle D. Protopapas, MSc, FRCS ${ }^{C}$

${ }^{a}$ Department of Critical Care Medicine University Hospitals Birmingham NHS Foundation Trust Queen Elizabeth Hospital Birmingham

${ }^{b}$ Institute of Inflammation and Ageing College of Medical and Dental Sciences Peri-operative, Critical Care and Trauma Trials (PACCT) Group

University of Birmingham, Edgbaston Birmingham

${ }^{c}$ Imperial College London London, United Kingdom

\section{References}

1. Bartfay SE, Dellgren G, Lidén H, Holmberg M, Gäbel J, Redfors B, et al. Are biventricular assist devices underused as a bridge to heart transplantation in patients with a high risk of postimplant right ventricular failure? J Thorac Cardiovasc Surg. 2017; 153:360-7.

2. Fitzpatrick JR III, Frederick JR, Hsu VM, Kozin ED, O'Hara ML, Howell E, et al. Risk score derived from preoperative data analysis predicts the need for biventricular mechanical circulatory support. J Heart Lung Transplant. 2008;27:1286-92.

3. Matthews JC, Koelling TM, Pagani FD, Aaronson KD. The right ventricular failure risk score a pre-operative tool for assessing the risk of right ventricular failure in left ventricular assist device candidates. J Am Coll Cardiol. 2008;51:2163-72.

4. Takayama H. Thinkers needed to improve biventricular assist device outcome. $J$ Thorac Cardiovasc Surg. 2017;153:368-9.

5. Lang RM, Badano LP, Mor-Avi V, Afilalo J, Armstrong A, Ernande L, et al. Recommendations for cardiac chamber quantification by echocardiography in adults: an update from the American Society of Echocardiography and the European Association of Cardiovascular Imaging. J Am Soc Echocardiogr. 2015;28:1-39.

6. Boegershausen N, Zayat R, Aljalloud A, Musetti G, Goetzenich A, Tewarie LA, et al. Risk factors for the development of right ventricular failure after left ventricular assist device implantation - a single-centre retrospective with focus on deformation imaging. Eur J Cardiothorac Surg. 2017; http://dx.doi.org/10.1093/ejcts/ ezx123 [Epub ahead of print].

7. Bellavia D, Iacovoni A, Scardulla C, Moja L, Pilato M, Kushwaha SS, et al. Prediction of right ventricular failure after ventricular assist device implant: systematic review and meta-analysis of observational studies. Eur J Heart Fail. 2017; http://dx.doi.org/10.1002/ejhf.733 [Epub ahead of print].

http://dx.doi.org/10.1016/j.jtcvs.2017.07.021 
Authors have nothing to disclose with regard to commercial support.

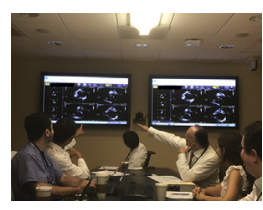

\section{"RIGHT VENTRICLE LOOKS BAD." "NO, IT DOESN'T." "YES, IT DOES." \\ Reply to the Editor:}

The title of our letter reflects a common refrain heard while reviewing echocardiograms during our multidisciplinary mechanical circulatory assist device meetings. Although echocardiograms are an essential component of patient evaluation and management both before and after left ventricular assist device implantation, there is no objective or widely accepted echocardiographic assessment of right ventricular (RV) function. We agree with Zochios and Protopapas ${ }^{1}$ in advocating for a better incorporation of echocardiography in this regard.

Previous attempts to incorporate echocardiographic parameters into a predictive RV failure model have been unsuccessful. This failure is in part because other clinical indicators, such as end-organ function or preoperative mechanical support, have demonstrated greater predictive power when incorporated into a statistical model. ${ }^{2,3}$ In addition, although the risk score by Fitzpatrick and colleagues ${ }^{4}$ includes severe preoperative RV dysfunction as seen on echocardiography, Fitzpatrick and colleagues ${ }^{4}$ acknowledge that this is not an objective measure. Ideally, we would have a simple and intuitive echocardiographic parameter (akin to ejection fraction for left ventricular function) that strongly correlates with RV failure after left ventricular assist device support. Our current lack of such a parameter suggests that there is an opportunity for us to achieve better understanding of the complex nature of RV anatomy and physiology and then to develop a novel metric through the use of modern imaging modalities.

Current 2-dimensional echocardiographic methods for the quantitative evaluation of RV contractility, such as fractional area change, tricuspid annular plane systolic excursion, and peak systolic tissue velocity of the RV lateral wall, have limitations. Fractional area change does not necessarily represent the ejection fraction of the entire RV, especially in the setting of significant tricuspid regurgitation. Tricuspid annular plane systolic excursion and tissue Doppler parameters assume that the function of a single segment represents the function of the entire RV, and both measurements are angle dependent. Although 3-dimensional echocardiography allows the direct measurement of RV volume without relying on geometric assumptions, it remains limited by the imaging quality of RV borders and by relatively low temporal and spatial resolutions. Assessment of tricuspid valve morphology may also add valuable information, but this is yet another isolated anatomic metric.

Studying the dynamic interventricular interaction may better discriminate patients at high risk for RV failure. ${ }^{5}$ For example, gradual deterioration of left ventricular preload and stroke volume often corresponds to worsening right-sided congestion, all of which can be identified on echocardiography. In addition, the latest software is promising in that it provides fast, reproducible, and accurate RV imaging. ${ }^{6}$

Despite the concerns described here, it is important to acknowledge that chronic RV failure is a clinical process that manifests through prolonged venous hypertension and insidious end-organ dysfunction, the degree of which dictates each patient's prognosis. Any attempt to correlate a clinical "snapshot," such as the information captured by a single echocardiographic study, is a tough task, if not an exercise in futility.

Masahiko Ando, MD, PhD, $M P H^{a}$
Koki Nakanishi, $M D, P h D^{b}$
Marisa Cevasco, $M D^{a}$
Koji Takeda, $M D, P h D^{a}$
Hiroo Takayama, MD, $P h D^{a}$
Divisions of Cardiothoracic and
Vascular Surgery and
${ }^{b}$ Cardiology
Columbia University Medical Center
New York, $N Y$

\section{References}

1. Zochios V, Protopapas AD. Echocardiographic correlates to right ventricular dysfunction and failure. J Thorac Cardiovasc Surg. 2017;154:1986.

2. Drakos SG, Janicki L, Horne BD, Kfoury AG, Reid BB, Clayson S, et al. Risk factors predictive of right ventricular failure after left ventricular assist device implantation. Am J Cardiol. 2010;105:1030-5.

3. Matthews JC, Koelling TM, Pagani FD, Aaronson KD. The right ventricular failure risk score: a pre-operative tool for assessing the risk of right ventricular failure in left ventricular assist device candidates. J Am Coll Cardiol. 2008;51:2163-72.

4. Fitzpatrick JR III, Frederick JR, Hsu VM, Kozin ED, O'Hara ML, Howell E, et al. Risk score derived from pre-operative data analysis predicts the need for biventricular mechanical circulatory support. J Heart Lung Transplant. 2008;27:1286-92.

5. Kukucka M, Stepanenko A, Potapov E, Krabatsch T, Redlin M, Mladenow A, et al Right-to-left ventricular end-diastolic diameter ratio and prediction of right ventricular failure with continuous-flow left ventricular assist devices. J Heart Lung Transplant. 2011;30:64-9.

6. Patil NP, Mohite PN, Sabashnikov A, Dhar D, Weymann A, Zeriouh M, et al. Preoperative predictors and outcomes of right ventricular assist device implantation after continuous-flow left ventricular assist device implantation. $J$ Thorac Cardiovasc Surg. 2015;150:1651-8.

http://dx.doi.org/10.1016/j.jtcvs.2017.08.032 